\title{
EXPLORING THE EUROPEAN CONSTITUTIONAL SPHERE. CENTRE - PERIPHERY PERSPECTIVE
}

\section{Introductory remarks}

An attempt to clarify such a vague notion as the "European Constitutional Sphere" definitely provokes substantial dilemmas. However, we should acknowledge that complexity and ambiguity are becoming, slowly but surely, distinguishing ingredients of the contemporary world. Thus, a sort of "multidisciplinary" approach appears to be the most appropriate methodological instrument in elucidating this concept. ${ }^{1}$ Multidimensional methodological jurisprudence, which is becoming increasingly popular, recognizes the growing importance of applying multiple methods and techniques, especially within legal and political studies. It needs to be emphasized that both law and politics are often described as ontologically complex and heterogeneous phenomena. From this perspective, the European Constitutional Sphere seems to be composed of various contrasting ideas and beliefs, which generate an overwhelming scepticism about the possibility of academic exploration of this arena. According to influential thinkers, acquiring insight and a full understanding of legal and political "Otherness" is almost unattainable. Unquestionably, a "cross-cultural" apprehension of a particular problem remains hard to achieve even within, or perhaps especially within, our $21^{\text {st }}$ century civilization. Could transgressing borders and exposing oneself to diversity become an accurate hermeneutical tool to explain the above-mentioned legal and political "utopia"?

The main hypothesis of this paper is that the European Constitutional Sphere can be perceived of as a battlefield in the process of globalization of law and politics, existing between the Centre and Periphery of our continent. Moreover, we are currently witnessing a spreading crisis in traditional international law, understood as a normative order pursued by nation states through conventions,

1 J.S. Bergé, Legal Application, Global Legal Pluralism and Hierarchies of Norms, "European Journal of Legal Studies" 2011, Vol. 4, Issue 2, p. 241-263. 
agreements, etc. The process of weakening both the institution of nation states and national identities brings about, slowly but steadily, a shift of power from the national to supranational level. We are gradually experiencing the emergence of a "Cosmopolitan Law" as a brand new post-modern legal order, extending beyond traditional concepts. ${ }^{2}$ However, it has yet to be explained whether this idealistic "Global Constitutionalism" is currently feasible and whether we as Europeans - are willing not only to tolerate but to truly accept "Others" within our legal and political communities?

\section{Pursuing the idea of law}

The question of the ontology of law (and politics) has never been ultimately resolved, despite numerous attempts to do so by legal theorists and political scientists. The tradition of legal and political studies is a perpetual process of conflicting interpretations, where different interpreters compete for audiences and adherents of their views. From this perspective, the analysis of the European Constitutional Sphere reveals one of the major challenges for jurisprudential thought, namely the autonomy of law. To explain this dilemma, we should consider whether a legal system can actually operate as a pure, coherent and absolutely consistent structure. However, before pursuing further arguments it should be stated at the outset that the discussion elaborated in this paper does not endorse any kind of "legal nihilism" or "de-construction".

When explaining the autonomy of law, we need to take into consideration the fact that the legal order frequently appears to be amorphous, open-ended and fragmented. ${ }^{3}$ In this sense, some thinkers depict the certainty of law as mythical and, in fact, groundless. The existence of objective criteria governing the creation and functioning of a juridical system is often questioned in the theoretical discourse. Legal reasoning does not always seem to be objectively justified. As a result, oppositions, antinomies and different narratives become the core of jurisprudential disputes. And because law appears to be far from monolithic, there is a growing necessity to reconcile both legal studies and political science, since the latter can actually reinforce fragile legal argumentation.

According to influential theorists, within contemporary European relations the law often becomes a kind of "vehicle" for politics. For this reason, an attempt to explain the relationship between globalization and constitutionalism seems justified. Nowadays, the phenomenon of hegemony and domination

2 J. Allard, A. Garapon, Les juges dans la mondialisation. La nouvelle révolution du droit, Seuil, Paris 2005.

${ }^{3}$ M. Young, Regime Interaction in International Law - Facing Fragmentation, Cambridge University Press, Cambridge 2012. 
in European politics appears to be effected, at least partially, by the transfers of legal norms. Definitely any distributions of power and/or redistributions of costs and benefits occur within the constitutional framework of a given community. From this perspective, the law is not neutral in political terms, but is rather deeply rooted in public argumentation and policy issues and, in consequence, motivated by external factors. As a result, law without politics is practically impossible, since it reproduces and bolsters the political and economic architecture of a given community. Moreover, numerous existing norms in fact legitimize a hegemonic system of obedience and domination, because power is frequently neatly hidden behind the law. One has to acknowledge that it is awkward to recognize law as autopoeisis - i.e. a juridical order independent from any extrinsic influences and incentives. The self-creation of law, as a separate system of social control, appears to be rather dubious, so we have no choice but to reduce the legal sphere to one of the social subsystems coexisting with the others.

Another controversial field of jurisprudence, to be analysed in this paper, is focused on the alleged pluralism of legal systems, i.e. the phenomenon which gradually undermines the traditional hierarchy and linearity between norms. ${ }^{4}$ More and more, this specific concept of legal philosophy is turning stable juridical orders into something resembling "patchworks". The plurality of law aims at facilitating the harmonious coexistence between various legal systems, such as supranational, national, non-territorial, etc. So it breaks with the traditional understanding of legal order distinctive for the 19th century jurisprudential concepts, which perceived law as a hyper-centralized and extremely hierarchical machinery. ${ }^{5}$ This phenomenon seems to be the sign of our times, which arises from the multiplicity of law-creating and law-applying bodies, especially the various courts and tribunals whose verdicts are supposed to be equally effective within national legal systems. Indeed, the coexistence of various centres of adjudication could be viewed as a constant feature of Cosmopolitan Law in statu nascendi. Perhaps the smooth annihilation of the Westphalian vision of law could unexpectedly create some opportunities for the reactivation of the neo-medieval stance in jurisprudence? It appears that the contemporary European legal integration could be called a rebirth of the medieval ius commune, because it presents similar features of pluralism, heterogeneity and polycentricism. The idea of law seems to be no longer homogenous, but strikingly flexible and even obscure, since it combines a mixture of domestic and external ingredients which 'softly' transform national legal orders. But does this, then, presuppose the emergence of Global Justice? Approaching

${ }^{4}$ J. Gilissen, Le pluralismejuridique, Université Libre de Bruxelles, Bruxelles 1972.

${ }^{5}$ N.W. Barber, Legal Pluralism and the European Union, "European Law Journal" 2006, No. 3, p. $19-48$. 
the problem of the proper application of national, supranational or non-territorial law in resolving conflicts between different legal systems definitely contributes to explaining why "global" is steadily displacing "international".

As was described above, the pluralism is noteworthy because, especially nowadays in Europe, there are multiple uncoordinated, coexisting and overlapping bodies of law. Numerous institutions, possessing different styles and orientations, may issue competing claims or impose conflicting demands. In consequence, the potential conflicts these various rulings may produce a great deal of uncertainty, which translates into jeopardy for individuals, who cannot be sure in advance which legal regime will apply to their situation. The state of this insecurity also creates some occasions for various groups within societies to opportunistically and arbitrarily choose from among coexisting legal regulations to realize their own desires. Moreover, it poses a substantial challenge for the legal authorities themselves, by erecting not only counterparts but, in fact, serious rivals for them. A multitude of separate tribunals and functionally distinct legal bodies, affiliated within specific fields of various legal orders that are not coordinated with each other, are creating networks beyond the effective control of any national authority.

Certainly, since the European project functions on a series of international agreements, it is legally pluralistic in the dual sense that the Member States have their own legal systems and that these systems interact with the broader continental legal order, a sort of combination with various internal diversities. ${ }^{7}$ Furthermore, the predominance of deliberations on legal pluralism at the European level typically include multiple forms of private regulations, private dispute resolution institutions, and the endeavours of private establishments like NGOs or business organizations, etc. ${ }^{8}$ Indeed, the mixture of these exclusive norms and regulatory bodies is considered to have forged the concept of legal pluralism, which refers significantly to the incorporation of customary and indigenous norms apart from the officially recognized public law.

\section{Cosmopolitan legal order - reality or utopia?}

The above general remarks on the nature of contemporary law can serve as a foundation for further analyses devoted to the idea of Cosmopolitan Law. The precedence of supranational law over national regulations, although generally acknowledged in the past, is today challenged and questioned within the Europe-

${ }_{6}^{6}$ J.L. Halpérin, Profils des mondialisations du droit, Dalloz, Paris 2009.

${ }^{7}$ G.P. Callies, P. Zumbansen, Rough Consensus and Running Code - A theory of Transnational Private Law, Hart Publishing, Oxford 2012.

${ }^{8}$ A. Hartkamp, European Law and National Private Law, Kluwer, Deventer 2012. 
an community. According to the German Federal Constitutional Court, the level of protection of fundamental rights becomes the actual factor deciding on the relation between national and supranational law. Therefore, the primacy of national constitutions functions mostly to ensure the adequate safeguard of fundamental rights and freedoms within the national community. It need to be emphasized that this attitude rests on the post-modern manner of defining juridical systems, which grants priority to the rights of individuals over the interests of nation states and international organizations. For the same reason, any transfers of competences from nation states to supranational bodies cannot deprive individuals of their basic rights.

The global dissemination of law definitely reveals symptoms of the crisis of nation states. The process of globalization supports the existence of numerous transnational political and economic entities, inducing nation states to resign, at least partially, from their sovereignty. From this perspective, globalization functions as a multi-dimensional phenomenon that fosters political, legal and economic exchange and/or interdependence at the international level. ${ }^{9}$ This dynamic is so powerful that it quite substantially reshapes existing legal and political bodies. Indeed, it is rather self-evident that the law plays a crucial role within the course of Europeanization. The exchange and interdependence spreading across the globe would be hardly possible without some kind of a legal system acting as a "medium". ${ }^{10}$ In this sense, Europeanization rests upon the circulation of legal institutions among various subsystems, shifting from the national to the European level, and vice versa. The above-mentioned distribution of regulations appears to be, in fact, a major prerequisite for establishing some sort of supranational area.

As a result, the core of the so-called Cosmopolitan Legal Order depends on the constant transfers from one domestic legal context to another, as well as to the global level. More and more these movements are affecting the lives of ordinary citizens in Europe, which seems to be a manifestation of the post-modern juridical concept. This Cosmopolitan Legal Order definitely demonstrates the extraordinary ability of combining and integrating various legal and political arenas which, in fact, can coexist and overlap fairly coherently. From this perspective, Europeanization as a legal and political phenomenon transforms our continent by leading it from separation to unity, from territory-based organizations to "despatialization", from state-centred configurations to supranational networks. ${ }^{11}$ Because of the above phenomena, nowadays the political community attempt to exceed beyond the boundaries of fading states.

${ }^{9}$ V. Graf Vitzthum, C. Prieto, R. Mehdi (eds.), Europe et Mondialisation - Europa und die Globalisierung, PUAM, 2006.

${ }^{10}$ R. Keohane, International Institutions: Can Interdependence Work?, "Foreign Policy" 1998, Vol. 110, p. 62-88.

${ }^{11}$ G. Teubner, Global Law without a State, Aldershot, Dartmouth 1997. 
The metaphor of a Cosmopolitan Legal Order, encompassing national and supranational law, appeals to those universal rights and duties which transgress state frontiers. Indeed, Cosmopolitan Law aims at functioning within the larger community by providing a common vision and set of values that substantially differs from the laws arising from the national institutions. Historically, nation states have been engaged in the process of nation-building, designed to produce a degree of common national identity across their entire territory and expected to be shared by all of their citizens. Nowadays, Cosmopolitan Law becomes a tool for creating a supranational community as a legal platform for the coexistence of various juridical systems and potentially "mosaic" identities. Perhaps the above-mentioned type of legal order could serve as a "vehicle" for a common European identity?

At this point, one should analyse a viable set of values for supranational law, at least in the European dimension. We - from the perspective of EU citizenship - consider such ideas as Enlightenment, capitalism, Roman law, democracy or modernization as feasible ideological foundations for the European legal (and political) culture (see Article 2 of the Treaty on European Union (TEU)). ${ }^{12}$

According to Article 6 point 3 of the TEU, human rights arise consequentially from the common constitutional traditions of the Member States. ${ }^{13}$ Moreover, the implementation of these fundamental values, especially since the establishment of the Copenhagen Criteria in 1993, functions as an condition for accession to the European Union. For this reason, any Member State responsible for even a minor violation of the above-mentioned principles can actually be subjected to severe sanctions imposed by the European community. Thus, one of the most meaningful stages of European integration may be correlated with the introduction of EU citizenship by the provisions of the Treaty of Maastricht. The substance of this "cosmopolitan citizenship", as it seems, is to ensure the safety of citizens as subjects of supranational rights and obligations. Possibly, EU citizens will operate in the future as individuals responsible for the shape of the political will of the European community. From this perspective, the concept of citizenship has, slowly but surely, come to exceed national contexts and focuses on the emerging supranational sphere. ${ }^{14}$ As a matter of fact EU citizens are relying more and more on the European Charter of Fundamental Rights as a sort of legislation enacted

12 "The Union is founded on the values of respect for human dignity, freedom, democracy, equality, the rule of law and respect for human rights, including the rights of persons belonging to minorities. These values are common to the Member States in a society in which pluralism, non-discrimination, tolerance, justice, solidarity and equality between women and men prevail."

13 "Fundamental rights, as guaranteed by the European Convention for the Protection of Human Rights and Fundamental Freedoms and as they result from the constitutional traditions common to the Member States, shall constitute general principles of the Union's law."

${ }^{14}$ J. Habermas, Citizenship and National Identity: Some Reflections on the Future of Europe, [in:] The Condition of Citizenship, ed. B. van Steenbergen, Sage Publications Ltd, New York 1994. 
to strengthen the primacy of community law over national legal orders. But can this Charter be acknowledged by virtually all Europeans as the primary source of their collective legal (and political) identity?

Nowadays, the democratic deficit at the supranational level seems to be quite noticeable. So before the Charter can be acknowledged a primary source of identity, one has to clarify whether Europeans are ready to establish a truly democratic community for themselves? The Cosmopolitan Law appears to be lacking democratic legitimacy simply because the European demos, especially in political terms, is strikingly ephemeral. For this reason, according to influential theorists, a sort of constitutional patriotism should go beyond narrow cultural citizenship and initiate a multi-level loyalty as a basic prerequisite for the emergence of a demos. However, this conviction raises profound questions about the current architecture of the common public sphere in Europe.

These days it is quite obvious that strong national identities dominate over any pan-European perspective. The contemporary European public arena is widely perceived as a weak and fragmented space of cacophony. So is it possible, under such circumstances, to achieve true dialogue and deliberation with reference to European legal and political affairs? The indispensable ingredient for a genuine constitutional discourse within the common public sphere should rest on basic tolerance, understood as respect for the different constitutional traditions of the Member States. ${ }^{15}$ Moreover, this public sphere needs to become a platform for dialogue between opposing legal and political regimes, with a great deal of acceptance for juridical "Otherness".

\section{Constitutional momentum for Europe}

Theoretically, constitutions are created by free peoples, whereas treaties are concluded between sovereign states. Hence all the discussions on a future constitution for Europe play a considerable role in the process of federalization of our continent. All these meaningful deliberations serve as an opportunity to put into practice the analyses devoted to the legal and political identity of Europe. However, the politicians are not particularly willing to consider the axiomatic core of European constitutionalism publicly. Instead, they are rather keen on throwing about stereotypes and prejudices within their passionate public debates. Yet there is no lack of issues requiring discussion, especially with reference to our legal identity within the European public sphere. As was elucidated above, the German Federal Constitutional Court established considerable limits on the process of integration with respect to the protection of fundamental rights and national constitutional

${ }^{15}$ H. Ruiz Fabri, M. Rosenfeld, Repenser le constitutionnalisme à l'âge de la mondialisation et de la privatisation, SLC, Paris 2011. 
identities. From this perspective, the juridical harmonization and/or unification of Europe cannot, in fact, damage the "essence" of the national constitutional identities of the Member States. In this sense, our national constitutional rights seem to be safeguarded against any unauthorized interference by the European Constitutional Sphere, regardless of the origins of any such assault. So are we really capable of abandoning our petty and unflattering quarrels in order to develop some sort of mutual recognition of a common constitution for Europe?

The Member States themselves are the major actors claiming the right to determine the political and social conditions for living together in Europe. The European Union itself cannot be perceived as an independent organization enjoying its own legitimacy, since it does not possess the capacity to "self-constitute". Indeed, Brussels may not design competences for itself (i.e. Kompetenz - Kompetenz), which appears to be a significant proof of rather insubstantial foundations of the EU's institutional architecture. What we have learned from the ruling of the German Federal Constitutional Court seems to be the conviction that the absolute primacy of EU law simply does not exist, because the unreflective recognition of such would mean loss of the ability to protect the "essence" of the constitutional identities of the Member States. ${ }^{16}$ These fundamental rights truly cannot be challenged by juridical provisions emanating from the EU's legal sphere, in spite of the fact that the Treaties undoubtedly have created a new juridical order. The principle of direct application of the acquis communautaire appears to secure the interests of EU citizens, and the Member States are obliged to ensure the effectiveness of EU law. But it needs to be emphasized that the Brussels cannot 'gradually' deprive the Member States of their core sovereignty, at least according to the German Federal Constitutional Court - in such areas as criminal law, police, armed forces, fiscal policy, culture, family law, education, etc. In this sense, the European project, governed by the principles of subsidiarity and proportionality, becomes a sort of hybrid juridical system composed of both national and supranational orders as equivalent counterparts. ${ }^{17}$ However, the German Federal Constitutional Court indicated that the national constitutional courts retain the "right to have the last word" whenever settling the fundamental disputes between national and supranational legal regimes.

How can we achieve the inclusion of all EU citizens within the above-mentioned differentiated community? As was mentioned, the lack of a collective will and a European demos undermines efforts to generate a truly common European Constitutional Sphere. Perhaps combining multiculturalism and legal pluralism within one community operating at the supranational level should be considered as totally naïve? However, European integration possesses an impressive record

${ }^{16}$ Ch. Tomuschat, The Ruling of the German Constitutional Court on the Treaty of Lisbon, "German Law Journal" 2009, Vol. 10, No. 08.

${ }_{17}$ M. Le Barbier-Le Bris, L'Union européenne et la gouvernance mondiale-Quel apport avec quel sacteurs?, Bruylant, Bruxelles 2012. 
of overcoming antagonisms between nations in our continent, since it provides a path for dealing with mistrust and intolerance. Moreover, according to Article 3 of the TEU, Brussels is obliged to preserve an opulent cultural and linguistic diversity, arising from both the Member States as well as Europe's cultural heritage. ${ }^{18}$ Thus while it seems obvious that the European Constitutional Sphere must respect national constitutional identities, less obvious is the fact that at the same time these identities restrain, at least to some extent, the process of legal and political convergence in Europe.

Currently, the processes of constitutionalization of the supranational sphere becomes one of the most discussed and yet ambiguous phenomena. ${ }^{19}$ It needs to be emphasized that each Member State's national constitution should be interpreted from a pro-European perspective. Although national constitutional identities set significant limits on the process of integration, the primacy of EU law, together with the pro-European interpretation of domestic laws as foundations of the European Constitutional Sphere, could lead to the erosion of national legal and political identities. In fact, it seems difficult to accomplish the process of Europeanization without erecting some sort of supranational constitution for Europe. Definitely, a minimum common legal culture is desperately needed for the foundation of a legitimate community of individuals sharing the feeling of belonging. But is it possible to achieve a truly mutual perception for the hierarchy of norms within the European Constitutional Sphere? The noticeable feature of the European legal culture has become the appearance of heterogeneity, which remains at the same time the main purpose of the attempts at significant harmonization.

The nature of the European Constitutional Sphere appears to be pretty dynamic. It is impossible to separate completely legal and political discourses from each other when considering the European constitutional arena. ${ }^{20}$ Without politics, any answer to the question concerning the necessity of a constitutional identity would be substantially incomplete. So the solution to this dilemma transgresses beyond juridical deliberations. It seems evident that only within various political discourses are we, or will we be, able to identify what we believe to be the core of our political community, as well as to choose the concept of citizenship we wish to pursue. Thus, the political sphere becomes a sort of "medium" by which our community attempts to challenge its own fate.

Regardless of whether it achieves true legal transgression, it seems obvious that Cosmopolitan Law endeavours to create a multi-dimensional order. The Europeanization of juridical space is constantly undermining traditional loyalties

18 "[The Union] shall respect its rich cultural and linguistic diversity, and shall ensure that Europe's cultural heritage is safeguarded and enhanced."

${ }^{19}$ Ch. Joerges, E.U. Pettersmann (eds.), Constitutionalism, Multilevel Trade Governance and Social Regulation, Hart Publishing, Oxford 2006.

20 J. Klabbers, A. Peters, G. Ulfstein, The Constitutionalization of international Law, Oxford University Press, Oxford 2009. 
and relationships within our continent. The multi-level public sphere appears to be organized on the principle of preservation of national, cultural and religious diversities. It emphasizes the importance of various channels of communication between EU citizens. The empowerment and articulation of their will becomes the basic requirement for establishing the European Constitutional Sphere, which can be perceived of as a sort of agora used by societies to acquire knowledge about the common good.

In theory, the public sphere consists of a search for harmony and consensus by providing the space for disputes and confrontations. By paving the way for democratic resolution of conflicts, it ensures legitimacy for the entire construction of a given community. But are those individuals who potentially represent the European demos really willing and able to discuss European issues within the framework of their national public spheres? It seems undeniable that today there is no single demos, but rather 28 demoi across the European Union. All these national public spheres differ substantially in their interpretations of European affairs. There is virtually no viable community of communications consisting of individuals considering themselves as eligible participants in the European public discourse. The appearance of the above-mentioned issues and state of affairs in our media seems to be rather scarce and disappointing, to put it mildly. The prevailing national perspectives on European issues, together with an exceptionally low level of awareness, only reinforces traditional prejudices and stereotypes. Perhaps the concept of a national public sphere does not necessarily correspond to the idea of a 'community' at a supranational level? To be frank, contemporary European affairs are somehow deemed not relevant for EU citizens, since Brussels does not possess extensive competences to deal with everyday concerns (i.e. education, health care, pensions, etc.). From this perspective, the European project becomes a domain of narrow circles composed of elites focused on their exclusive interests, ${ }^{21}$ while blistering debates are an essential element of viable public arenas, within which democratic communities need spaces for the numerous social interactions necessary to sustain their existence. The more we argue and engage, the more we participate and create a genuine political community.

The perception of citizens from other Member States as legitimate participants in the national debates requires a sense of identification with European affairs. Clearly, feelings of belonging and loyalty both emerge through a variety of discourses. So the "community of law" should arise from distinctive debates aimed at developing a common way of interpreting public concerns. For this reason, the European Constitutional Sphere ought to be constantly negotiated. Indeed, public deliberations of stubborn EU citizens would increase awareness, emancipation, knowledge and criticism within our legal and political agora. The Eu-

${ }^{21}$ P. Graziano, M.P. Vink, Europeanisation. New Research Agendas, Palgrave McMillan, Basingstoke 2007. 
ropean demos, as an indispensable ingredient of a common juridical area, can only gradually appear through the recognition of other EU citizens as members of the same political community. Unfortunately, a truly European public sphere still remains barely perceptible, if not barely possible, since the collective European identity simply does not exist. Europe is not a community of communication, hardly a community of memory and only to a very limited extent a community of politics, whereas it is literally these kinds of communities where collective identity develops. The European project itself seems to be superficial, ephemeral and, in fact, not very applicable to ordinary citizens. So are we - as Europeans - really prepared for the creation of a meaningful community of communication, presupposing some degree of collective identification with each other's fate?

It needs to be emphasized that EU constitution making is a very challenging task, because it presents Europe's citizens as individuals with a variety of problems. The "essence" of the process rests on the permanent construction, diffusion and institutionalization of formal and informal rules, procedures, paradigms and norms. However, the phenomenon of asymmetry of rationalities inhibits the emergence of the European Constitutional Sphere, because this legal and political space seems to be filled up primarily with the interests of dominant actors. In the opinion of authoritative thinkers, each state needs three rudimentary elements for its existence, i.e. territory, people and power. ${ }^{22}$ Moreover, each constitution determines fundamental principles and establishes proceedings organizing the state's institutional architecture. But one has to ask if it is really possible to achieve such a legal and political construction at the supranational level?

The question as to whether the European Court of Justice (ECJ) or the constitutional courts of the Member States are legitimized to analyse EU law in terms of its compliance with national constitutions has been controversial for many years. The ECJ is accepted as the only body that has the ability to interpret the rules of the acquis communautaire, but it does not have jurisdiction to examine national provisions. The constitutional courts of the Member States are the legitimate tribunals to review the compatibility of national regulations with the constitution, but according to the ECJ, they do not have the authority to examine the constitutionality of EU law. Who, then, would be the final arbiter of the constitutionality of the law in the European Constitutional Sphere, assuming the existence of a common European legal area with many autonomous and independent legal systems? Are cases of a conflict between the constitutional systems of Member States and the European legal order itself inevitable? In spite of their agreement on the primacy of the acquis communautaire with reference to national legal systems, state constitutional courts, under certain exceptional conditions, are authorized to resist the application of a community law when

${ }^{22}$ H. Kelsen, General Theory of Law and State, The Lawbook Exchange Ltd., Clark, NJ 1945; reprint of the first edition, 2007. 
it is contrary to specific and fundamental provisions of their national constitutions. Undoubtedly the primacy of EU law is a fundamental principle of the European Constitutional Sphere, as is constantly reaffirmed in the practice of the ECJ. This primacy, however, is still not accepted without reservation by the constitutional courts of the Member States in fundamentally important matters. Thus, there is a growing necessity to create a sort of "community of national constitutional courts", which would have a mitigating impact on the interpretation of juridical provisions within the European Constitutional Sphere..$^{23}$

As was mentioned above, the European common legal area cannot be formed only by legislative means. This phenomenon is a pluralistic "mosaic" of heterogeneous juridical procedures, patterns and practices driven, at least to some extent, by political reasons. One has to acknowledge that within the national sphere the introduction of the acquis communautaire has basically intensified the level of legal uncertainty. The harmonious national hierarchy of norms has been disturbed by global provisions which appear to be hard to anticipate and, in fact, not always easy to control. It is not only the huge amount of EU legislation which has to be implemented by the Member States. These "legal transplants" are scarcely autonomous and they frequently interact with other domains of public life. The European Constitutional Sphere is, by definition, a fragmented and/or polycentric phenomenon, so this juridical order cannot be understood through theoretical tools borrowed from the traditional state-centred concepts. However, those pluralistic tendencies are delicate and can easily be hampered if, for instance, various nationalist movements gain further acceptance in our continent. In fact, sovereign nations are deeply involved in the constant design of the European Constitutional Sphere, and they enjoy essential power and legitimacy.

Thus, considerations concerning the European Constitutional Sphere as a sort of legal and political order must extend far beyond the orthodox thought arising from the doctrines concerning states. ${ }^{24}$ It seems that the hardest thing to accept is the specificity of the acquis communautaire. It must be admitted that modern states are no longer utterly free legislators. It is estimated that nearly two thirds of normative acts in force today in the EU Member States have their source in EU provisions. This is not to say, however, that the national level has disappeared. It still carries its own "normative hierarchy", even if certain elements of these hierarchies have been substantially reshaped under the influence of the global legal order. $^{25}$

${ }^{23}$ T. Olson, P. Cassia, Le droit international, le droit européen et la hiérarchie des normes, PUF, 2006.

${ }^{24}$ J.Y. Chérot, B. Frydman, La science du droit dans la globalisation, Bruylant, Bruxelles 2012.

${ }^{25}$ Ch. Knill, A. Lenschow, Compliance, Competition and Communication: Different Approaches of European Governance and their Impact on National Institutions, "Journal of Common Market Studies" 2005, Vol. 43, No. 3, p. 37-59. 


\section{Contemplating the Centre - Periphery dialogue (in place of conclusions)}

The cohabitation between the European legal space and national juridical orders requires a vast and complicated system of enabling procedures, which in general favour the Western, highly industrialized, states. It seems that these states, forming the so-called Centre, are responsible for drafting the Cosmopolitan Legal Order, mainly through the process of diffusion of norms. It needs to be underlined that competition among legal institutions is slowly but surely becoming a permanent feature of our times. With respect to this challenge, the Centre still holds the position of incontestable leader. Indeed, the founders of the European project are predominantly liable for the proliferation of international, supranational and/ or multinational rules and proceedings. Definitely, the core of the European Constitutional Sphere possesses a sort of normative character, whereas the Peripheries are only capable of receiving and adapting standards and regulations developed by the leading Western states. ${ }^{26}$ Viewed in this perspective, the Centre universalizes its own interests and extends beyond its boundaries to reach, in both legal/ normative and economic terms, the Peripheries. ${ }^{27}$ It appears that the above-mentioned Cosmopolitan Legal Order, as a kind of post-modern "battlefield", consists of pluralistic, polymorphic and polycentric law disseminated primarily for political reasons.

${ }^{26}$ F. Schimmelfennig, U. Sedelmeier, Governance by Conditionality: EU Rule Transfer to the Candidate Countries of Central and Eastern Europe, "Journal of European Public Policy" 2004, No. 4, 64-90.

${ }^{27}$ A. Niedźwiecki, Is the Division between Centre and Periphery of European Integration Inevitable?, "Jindal Journal of International Affairs" 2012, Vol. 2, Issue. 1, p. 38-57. 